Adaptations to resistance training in young males Journal of Strength and Conditioning Research Publish Ahead of Print DOI: 10.1519/JSC.0000000000001780

1

2

3

5

6

8

9

10

11

12

17

18

19

20

21

22

\title{
Maturation-related differences in adaptations to resistance training in young male
}

\section{swimmers}

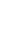

Jason Moran ${ }^{1}$, Gavin R.H. Sandercock ${ }^{1}$, Rodrigo Ramírez-Campillo², John-James Wooller', Spiros Logothetis ${ }^{1}$, Patrick P.J.M. Schoenmakers ${ }^{1}$, Dave A. Parry ${ }^{1}$

1. Centre for Sports and Exercise Science, School of Biological Sciences, University of Essex, Wivenhoe Park, Colchester, CO4 3SQ, United Kingdom

2. Department of Physical Activity Sciences, University of Los Lagos, Campus of Chuyaca, Av. Fuchslocher n 1305,5290000 ,

Chile

\section{Corresponding author details}

Jason Moran, Centre for Sports and Exercise Science, School of Biological Sciences, University of Essex, Wivenhoe Park, Colchester, CO4 3SQ, United Kingdom jmorana@essex.ac.uk,+447510833714 
24

This study examined the effects of resistance training on muscular strength and jump performance in young male swimmers. It was hypothesized that adaptations would be of a lower magnitude in less mature (Pre-peak height velocity [PHV]) than in more mature (PostPHV) subjects. Fourteen Pre- (-1.8 \pm 1.0 years $)$ and 8 Post-PHV (1.6 \pm 0.5 years $)$ swimmers undertook a 30 minute, twice-weekly resistance training program for 8 weeks. They were compared with matched control groups (Pre-PHV: $-2.0 \pm 1.1, \mathrm{n}=15$; Post-PHV: $1.2 \pm 1.0$, $\mathrm{n}=7$ ). The effects on lower body isometric strength (LBS), measured with mid-thigh pull, and vertical jump (VJ) height in the Post-PHV group were large (effect size: 1.3 [0.4 to 2.2]) and small (0.4 [-0.4 to 1.2]) respectively. Effects on LBS and VJ height in the Pre-PHV group were moderate (0.8 [0.1 to 1.4$])$ and trivial $(0.2[-0.5$ to 0.8$])$ respectively. Estimates in the Post-PHV control group (LBS: $0.7[-0.2$ to 1.6$] ; \mathrm{VJ}: 0.2[-0.7$ to 1.0$]$ ) and the Pre-PHV control group (LBS: 0.1 [-0.5 to 0.7$]$; VJ: $-0.3[-0.9$ to 0.3$]$ ) may indicate the extent to which maturation could contribute to the performance changes seen in the respective training groups. LBS and VJ are trainable, but to different magnitudes, in Pre- and Post-PHV swimmers. Following appropriate foundational training to establish technical competency, twice-weekly resistance training sessions of 30 minutes duration, comprising 3 sets of 4 exercises can be effective in Pre-PHV and Post-PHV youth.

Keywords: Trainability, strength, youth, athletes, swimming. 


\section{INTRODUCTION}

Maximal strength is the maximum force skeletal muscles can exert in an action (29). Strength is well correlated with sprint $(r=0.672)$ and jump $(r=0.760)$ performance $(7)$ and can help to reduce injury rates (16). Physical strength is also required to carry out fundamental movement skills and to underpin long term commitment to physical activity (32). Recommendations suggest no minimum age for participation in resistance training but youth should be technically proficient before embarking on a program (9). On this, neuromuscular coordination can vary in athletes of the same chronological age (43) whilst adaptations can differ between youth of disparate maturity status $(40,53)$ due to issues relating to movement efficiency and hormonal profile (43). These are important considerations in programing as guidelines for exercise in youth have thus far been generic, particularly for less mature or experienced children who may need to overcome issues relating to strength and motor control to optimise performance.

Current literature is undermined by a number of limitations relating to the biological maturity status of youth in addition to the specificity of the training stimulus with respect to stages of maturation. Historically, controlled trials $(31,47,61)$ have demonstrated improvements in strength following exposure to resistance training but have measured maturity status in different ways making comparisons to recent studies difficult. Over the last number of years, researchers have started reporting the maturity offset (years before and after peak height velocity $[\mathrm{PHV}](41))$ of trial subjects $(40,53)$ and more recently, the first controlled studies, which measure maturity offset in resistance-training athletes $(20,52)$, have emerged. Both of these studies involved youth soccer players who were subjected to concurrent training modalities including squat, sprint and jump exercises on a twice-weekly basis with the authors examining the effects on equivalent performance parameters. However, only one resisted exercise was performed in the program each day. 
Maturity offset (41) is an objective and practical method to assess maturation and is used in professional sports $(59,63)$. Though not without limitations $(41)$, the method has been used to form grouping variables in a variety of recently published interventions and reviews examining training types in youth $(33,40,42,43,48,53,54)$. Additionally, many researchers have failed to measure programs' effects on a measure of maximum muscular strength, preferring instead to assess responses in jumping and sprinting performance $(21,33,48$, 55). This is an important consideration in light of the specificity of adaptive responses to different training modalities (60). Also, recent controlled trials in youth demonstrated moderate to large gains in strength over a 6 week period but because resistance training was combined with sprint and plyometric training, it is difficult to specify the effect of resistance training in youth of a certain maturity status $(20,52)$. Furthermore, controlled studies have generally not compared adaptations in groups of different maturity status as delineated with the maturity offset. Two recent studies $(40,53)$ did adopt this approach but did not include control groups making it difficult to partition the effects of training and maturation. On this, Radnor et al. (48) and Lloyd et al. (33) did include control groups and a measure of maturity status but preferred to assess resistance training's effect on jumping and sprinting performance.

To date, no researchers have sought to address all of the above limitations within the same study and this undermines the quality of inferences that can be made from the literature. The purpose of this study was to examine the effects of resistance training, deliberately without sprints and plyometrics, on performance in Pre-PHV and Post-PHV male subjects, incorporating control groups and a measure of muscular strength. Recent evidence on strength training in youth has been somewhat equivocal. A meta-analysis by Behringer et al. (3) showed that younger trainees had greater increases in motor performance in response to resistance training. However, recent non-controlled trials have shown that resistance training has had greater effects on muscular strength in more mature youth athletes $(40,53)$. On that 
basis, it was hypothesized that adaptations in strength and power would be of a larger magnitude in more mature (Post-PHV) than in less mature (Pre-PHV) youth swimmers.

\section{METHODS}

\section{Experimental approach to the problem}

This study was carried out to assess the effects of resistance training on performance in PrePHV and Post-PHV male swimmers with a view to testing the hypothesis that the more mature group (Post-PHV) would demonstrate greater adaptations. Addressing the limitations of previous research, it was a deliberate design feature to include training groups of different maturation status to facilitate testing of the hypothesis. Accordingly, the groups were divided on the basis that synergistic adaptations to resistance exercise may occur due to the combined effects of training and maturation in more mature (Post-PHV) youth (14). Additionally, control groups were incorporated to account for non-training related changes in performance while a measure of biological maturity and, also, muscular strength was used to determine if changes in strength were dependent on maturity status. The measure of biological maturity status proposed by Mirwald et al. (41) was utilised to differentiate the study groups as it is a commonly used method in youth sport. Before and after the 8 week training intervention period, tests were carried out to assess upper body strength (UBS [hand grip peak force]), vertical jump (VJ) and lower body strength (LBS [isometric mid-thigh pull peak force]) as these were considered to be measures that would be likely to show an effect due to the training stimulus (14).

\section{Subjects}

The study was approved by the university's ethics committee and written informed consent was obtained from parents and subjects. It was undertaken in accordance with the Declaration of Helsinki. Youth swimmers were recruited through local swimming clubs. The experimental group $(n=22)$ was recruited from a single club to provide access to training facilities. To avoid contamination, the control group $(n=22)$ was drawn from multiple clubs 
$124(n=4)$. Because of this, randomization was not feasible. The characteristics of the subjects 125 are in Table 1. Subjects ranged from -3.9 to +3.1 years either side of PHV and were divided 126 into Pre-PHV (Experimental: $\mathrm{n}=14$; Control $=15$ ) and Post-PHV (Experimental: $\mathrm{n}=8$; 127 Control = 7) groups for analysis, as recommended by Mirwald et al. (41) (Pre-PHV $=<0.0$ years from PHV; Post-PHV $=\geq 0.0$ years from PHV).

\section{[Table 1 near here]}

\section{Procedures}

Subjects performed fitness tests in the week before and the week after the training intervention. Testing was carried out by a team of sports scientists from the university's Sports and Exercise department. To estimate maturity status, anthropometric measurements were taken and entered into an equation to predict maturity offset (41). Following this, the tests of UBS, VJ and LBS were undertaken. Sitting and standing height were measured with a stadiometer (Seca, Leicester, United Kingdom) and body mass with a portable scales (HoMedics Group Limited, Kent, United Kingdom).

UBS was measured with a Takei T.K.K.5001 GRIP A handgrip dynamometer (Takei Scientific Instruments Co. Ltd, Tokyo, Japan). Excellent test-retest reliability $(r=0.97)$ was observed for this measure which was in line with previous work (46). The dynamometer was adjusted to the hand size of each subject (5). Hand span was measured with tape and was taken as the distance between the little finger and the thumb when the hand was widely opened, with optimal grip spans corresponding to previous measurements (11). The dominant hand was used with the subject in a standing position, the elbow extended and the wrist held neutral. The used arm was allowed to deviate from 180 degrees of flexion to near 0 degrees. The subjects were given a verbal countdown to performance of " $3,2,1$, squeeze" and exerted maximal force for a period of 5 seconds. Following two efforts with at least 2 minutes of rest between each, the highest observed score was recorded for analysis (5). The 
digital version of this equipment has been shown to be acceptably reliable across trials (inter-trial difference: $0.3 \pm 2.5 \mathrm{~kg})(46)$.

To assess vertical jump, a Newtest Powertimer jump mat (Newtest OY, Oulu, Finland) was used. Excellent test-retest reliability $(r=0.92)$ was observed for this measure which was in line with previous work (57). Jump tests in youth have shown this apparatus to be highly reliable (39). Subjects executed a downward movement to a self-selected depth before performing an explosive extension of the lower-body limbs to jump as high as possible (8). To facilitate maximal performance, participants were permitted to utilise an arm-swing movement as desired during the jump (22). There was at least one minute's rest between efforts and the highest of three trials was used in the analysis.

LBS was measured with a portable cable pull apparatus (Takei A5002, Fitness Monitors, Wrexham, United Kingdom) which has a high intraclass correlation coefficient $(r=0.98)(28)$. Excellent test-retest reliability $(r=0.89)$ was observed for this measure which was in line with previous work (28). The apparatus can be viewed in Figure 1. Subjects were instructed to assume an upright body position with the knees bent to approximately 160 degrees (28). The lumbar spine was arched and the trunk was inclined forward such that the pulling handle rested halfway up the thigh between the midpoint of the patella and the iliac crest (6). Following the assumption of a safe body-position (2), subjects were given a verbal countdown to performance of " $3,2,1$, pull". With verbal encouragement (2), each subject exerted maximal force for a period of 5 seconds (6). Between each effort, subjects were instructed to rest for 3 minutes (6) and the best of two trials was used for analysis. The unit of measurement for the MTP was kilogram-force (kgf) with one unit being the equivalent of $9.806 \mathrm{~N}(58)$.

The three performance tests were undertaken in the order described with the difference between the coefficient of variation for baseline and follow-up measures ranging from $2.4 \%$ to $3.9 \%$. 


\section{Training}

177 The resistance training programme (Table 2) conformed to the guidelines for youth of the National Strength and Conditioning Association (13) and was delivered every day by the lead researcher who is an accredited strength and conditioning coach (UKSCA), and other qualified personnel. Prior to the beginning of each session a general warm-up (5-10 mins), consisting of skipping, crawling and various other upper and lower body movements, was performed. Training sessions were scheduled on four days each week and subjects were instructed to attend on two non-consecutive days. Prior to undertaking the 8 week intervention study, subjects engaged in an introductory week during which they were familiarised with the session format and proper exercise technique.

\section{[Table 2 near here]}

During the sessions, subjects were instructed to use manageable loads such that safe and technically proficient performance was not compromised. Each subject was encouraged to lift the maximum weight possible for the prescribed number of repetitions. When subjects were capable of performing more than the prescribed number of repetitions, they were asked to increase the load by between $5 \%$ and $10 \%$. In such cases, they were permitted to perform the work set to near muscular failure before adjusting the load to the higher level. Conversely, if they were unable to complete the work set, they were instructed to decrease the load by $5 \%$ to $10 \%$. For the push up exercise, subjects were given a repetition guideline up to a maximum of 30 seconds (each side), and 1 minute respectively. In the final week of each four week cycle, maximum repetitions or time were encouraged up to the point that proper technique could be maintained on each exercise. 
201 As available training time was limited, sessions followed a specific format. The first sets of all

202 four exercises were performed in a continuous manner with low-intensity mobility exercises

203 used as active rest between each. These included side-lying rotations, leg lowering, floor slides and hip-flexor stretching. Using phase 1 as an example, the subjects would perform a single set of goblet squats, using side-lying rotations as a means of active rest before performing a single set of push ups, followed by the leg-lowering mobility exercise and continuing on to the third and fourth exercises accordingly. After this, 2 to 3 minutes of complete rest was taken before moving on to the second set of goblet squats and performing all subsequent exercises in a continuous manner once again. This form of "super-setting" is considered to be effective for carrying out resistance training when available time is a limiting factor (26) and exercises were arranged in such a way that upper and lower body movements were alternated to preserve technical competency in each. After 4 weeks of the intervention, the resistance exercises were progressed to maintain subjects' engagement and to increase the demands of the program.

The average ratio of subjects to coaches in the intervention was approximately 5 to 1 . The average attendance rate during the intervention was $89.2 \%$. To complete the study, a subject must have attended $75 \%$ of all training sessions to ensure that a sufficient volume of training was undertaken. Subjects tracked progress in a diary which was observed by the lead researcher. Also, to estimate workload, immediately after each training session, subjects reported their perceived exertion (RPE) for the entire session on a 1 to 10 scale. This figure was multiplied by the training session duration in minutes to establish a 'sessionRPE' score (19). 


\section{Statistical analysis}

228 Magnitude-based inferences were preferred to traditional null hypothesis testing which can be biased by small sample sizes (51) and can be ineffective in gauging practical importance (24). Effect sizes were interpreted using previously outlined ranges $(<0.2=$ trivial; $0.2-0.6=$ small, $0.6-1.2=$ moderate, $1.2-2.0=$ large, $2.0-4.0$ = very large, $>4.0=$ extremely large) $(24)$. An effect size of 0.2 was considered to be the 'smallest worthwhile change' (56). The estimates were considered unclear when the chance of a beneficial effect was high enough to justify use of the intervention, but the risk of impairment was unacceptable. An odds ratio of benefit to impairment of $<66$ was representative of such unclear effects (40). This odds ratio corresponds to an effect that is borderline possibly beneficial ( $25 \%$ chance of benefit) and borderline most unlikely detrimental ( $0.5 \%$ risk of harm). This was calculated using an available spreadsheet (23). Otherwise, the effect was considered as clear and was reported as the magnitude of the observed value, with the qualitative probability that the true value was at least of this magnitude (40). The scale for interpreting the probabilities was as follows: possible $=25-75 \%$; likely $=75-95 \%$; very likely $=95-99.5 \%$; most likely $>99.5 \%$ (24).

Uncertainty in the effect sizes was represented by $90 \%$ confidence limits. Effects were considered unclear if the confidence interval overlapped thresholds for substantial positive and negative values. Otherwise, the effect was clear and reported as the magnitude of the observed value with a qualitative probability $(24,40)$. The utilised confidence limits of $90 \%$ are important in intervention studies in which one is presented with an inexpensive intervention that is most unlikely to be harmful, but likely to be at least trivially beneficial (23). 


\section{RESULTS}

253 Effect sizes and their descriptors and likelihood estimates of beneficial effects are shown in

254 Tables 3 (baseline to follow up) and 4 (follow up only).

\section{[Table 3 near here]}

256

257

258

259

260

261

262

263

264

The within-group baseline to follow-up analysis showed LBS increased across both groups and was of large magnitude in the Post-PHV group and moderate in the Pre-PHV group. Comparison of follow-up tests in both Pre-PHV and Post-PHV groups and their controls were reflective of this finding. The Post-PHV control group improved LBS to a greater extent than the Pre-PHV control group. Predominantly small and trivial changes were seen in UBS across experimental and control groups in both maturity categories. The Post-PHV group showed a small 'likely beneficial' effect for VJ and the Pre-PHV group showed a trivial effect in the within-group analysis. However, the between-group comparisons showed substantially larger post-intervention changes in the Pre-PHV group than in the Post-PHV group. Once again, the Post-PHV control group showed larger changes than the Pre-PHV group.

\section{[Table 4 near here]}

The training load data for the training intervention can be viewed in Figure 2 and Table 5. Only small and trivial changes were found between both experimental groups.

[Figure 2 near here]

\section{[Table 5 near here]}

\section{DISCUSSION}

This study compared the effects of a resistance training program in male swimmers of differing biological maturation status. It was hypothesized that more mature (Post-PHV) subjects would adapt at a greater magnitude than less mature (Pre-PHV). The study sought to account for limitations in previous research by including control groups, measures of 
muscular strength and comparable maturity groups within the same investigation, something which has not previously been achieved. The most important finding was that strength seems more trainable in Post-PHV youth than in Pre-PHV and the effect sizes for LBS in each group confirmed this. Also notable was that despite the pure intervention effect on VJ being smaller in the Pre-PHV group, VJ performance could be more responsive to resistance training in Pre-PHV.

Previous interventions in youth athletes $(40,53)$ have shown that resistance training in the Pre-PHV stage may be less effective for increasing strength than it is in the Post-PHV stage. Meylan et al. (40) found that maximal strength was less trainable in Pre-PHV athletes and more transient following a detraining period when compared to Mid- and Post-PHV athletes. Similarly, Rumpf et al. (53) reported that Pre-PHV athletes failed to improve resisted sprint performance as compared to a Mid-/Post-PHV group which showed significant increases. However, neither of these studies included a control group which makes it difficult to fully evaluate the training methods and impossible to differentiate between changes due to training and biological maturation.

Structural development of muscle mass can occur in response to hormonal changes during adolescence (32). Also, an influential factor in the ability to exert force is the cross-sectional area of a muscle (18). Accordingly, as the Pre-PHV group's ability to increase muscular size was likely lower than the Post-PHV group's, the less mature subjects may have been more dependent on neural mechanisms for the enhancement of strength. The lower effect size seen in Pre-PHV could be indicative of fewer available pathways of adaptation in comparison to the Post-PHV group. This is supported by previous research (62) which revealed that tendon cross-sectional area remained unaffected following resistance training in prepubertal children, despite an increase in tendon stiffness of $29 \%$. Moreover, it has been demonstrated that increased strength in prepubertal boys can occur without changes in muscular size with strength adaptations attributed to enhanced excitation-contraction coupling (50). 
303

304

305

306

307

308

309

310

311

312

313

314

315

316

317

318

319

320

321

322

323

324

Performance improvements are likely to occur due to the interaction between training and maturation $(13,44)$. Interestingly, moderate changes in LBS were seen in the Post-PHV control group. This contrasts with the changes in LBS in the Pre-PHV control group, which improved only trivially. The disparate effects observed in the control groups could suggest that maturation-related increases in strength influenced performance in the Post-PHV group though over the short study period this could also be argued to be unlikely. Alternatively, the size of the observed effect means that a learning effect or increased desire to perform well on the test cannot be ruled out as confounding factors.

Trivial increases and small decreases in UBS in the Pre-PHV and Post-PHV groups were matched by almost identical results in their respective control groups. This suggests that training exerted no effect on this measure, likely due to the nature of the training programme which, based on its configuration, seemed more likely to increase LBS than UBS. This underlines the importance of the specificity of the training stimulus; however, even in interventions that included exercises that targeted the wrist flexors, effects as measured by hand grip strength, were non-existent and small in 1-day (0.0, [-0.5 to 0.5$])$ and 2-days (0.33 [-0.2 to 0.9]) per week training groups (15).

The results of this study show that resistance training can enhance VJ performance in both Pre- and Post-PHV swimmers. Despite the pure intervention effect being lower in Pre-PHV, the between-group analysis showed that the effects on VJ were far larger in that group. However, it must be considered that an increase in body weight during Post-PHV could result in greater increases in absolute strength and bodyweight which could result in decreases in relative strength (64) and, thus, a reduced effect on VJ. Research has shown the effects of age, lean leg volume, body mass, altered muscle architecture and neuromuscular coordination on performance in youth (34) and this could partly explain why the Post-PHV group showed larger increases in LBS, which is dependent on absolute strength (37), than in VJ, which is dependent on relative strength (45). Conversely, as hypertrophic gains were less likely to play a role in Pre-PHV, VJ in that group may have 
been uninhibited by changes in bodyweight and reductions in relative strength. Reinforcing this, Lloyd et al. (33) reported predominantly larger changes in jump height in Pre-PHV youth in response to a variety of different training types, citing maturation-related changes in stretch-shortening cycle regulation as a potential mechanism. Nevertheless, the reader must consider that despite there being a larger post-intervention difference in the Pre-PHV groups, the raw increase in VJ was still greater in the Post-PHV group.

It is also important to note that the increases in VJ performance were far less than LBS over the 8 week intervention and plyometric studies of similar duration have reported larger effects on jump performance (42). This underlines the independent nature of different physical qualities (60) and suggests a need to incorporate a range of modalities into training programmes to specifically target multiple abilities. This may be particularly important in Post-PHV (33) when youth seem more receptive to a wider range of training adaptations (42, 43). Resistance training has been shown to be effective in increasing jump performance (33, 40). However, in many interventions training is carried out alongside sprint or plyometric training meaning that it is difficult to partition the effects of resistance training from those of other modalities. This is further convoluted by many researchers implementing a resistance training program but measuring only its effects on jumping or sprinting performance, and not strength.

In terms of resistance training programing, current recommendations for youth are broad $(13,30,32)$ and dose responses remain unclear (30). Furthermore, quantifying resistance training loads is a difficult task (30) and several methods have been proposed $(10,35)$. To establish a basis for comparison with other studies, subjects provided RPEs following each training session. Meylan et al. (40) reported mean RPEs as low as $3.7 \pm 1.3$ arbitrary units $(\mathrm{AU})$ in light training weeks and as high $6.1 \pm 1.5 \mathrm{AUs}$ in heavy training weeks. In comparison, this intervention showed mean RPEs of $6.6 \pm 1.0$ AUs with little variation over time despite the periodized nature of the training program. In adult males, RPEs of this magnitude have been equated to a mean exercise intensity of around $90 \%$ of $1 \mathrm{RM}$ across a 
resistance training session (10), but it remains to be proved if this is directly applicable to a youth population. The reported training RPEs and session-RPEs seem to indicate that training loads across both groups were relatively equal. In future studies, the reporting of RPEs could be a simple, but useful, way of standardizing training loads for comparison across interventions to approximate training intensity in heterogeneous programs. The method has been shown to be reliable in measuring resistance training intensities in adults (10).

As highlighted recently (38), research into the trainability of youth must satisfy several criteria such as the inclusion of control groups, the utilization of an assessment of biological maturity status and the direct comparison of responses in different maturity groups. A strength of this study is that it meets all of these criteria and also uses a measure of performance that is specific to the applied training stimulus. Many studies have met one or some of the above criteria but to our knowledge, no previous study achieves all. However, it does have some limitations. Several training studies $(4,17,49)$ have used similar statistical methods but with a smaller sample size ( $<10$ subjects) than that recommended by Hopkins (25) such that the sample does not misrepresent the population. In the current study, the Post-PHV training and control groups also have less than 10 subjects potentially limiting the findings' applicability to a wider population. Future research could replicate this study with a larger sample. Also, the randomization of subjects was not possible, though this is also a common drawback in many interventions studies. Mirwald's (41) method of measuring biological maturity status, though reliable, can lack precision. The division made between the maturity groups in the current study was made at the point of 0.0 years to/from $\mathrm{PHV}$ meaning that any individual who fell within 6 months proximity to this could have been wrongly categorised. However, as only 3 out of 44 individuals were within this range, it is unlikely that this affected the results to a great extent. Assessments of biological maturity may be reinforced with alternative measures such as that of Khamis and Roche (27) whilst a wider divison between groups may also be beneficial in research settings $(33,48)$. Also, 
though the performance measures utilised showed clear differences between groups, they do not necessarily explain the underlying mechanisms meaning more research is required. Lastly, though the subjects in the experimental groups were not carrying out another resistance training program, and just two reported informal resistance training experience, many were involved in other sports such as soccer and rugby. This could confound the results and their applicability to other populations, though almost all control subjects were also involved in other sports and did not demonstrate extensive performance changes.

Overall, strength and power are trainable to different degrees in Pre-PHV and Post-PHV swimmers but more mature individuals could be more sensitive to applied stimuli potentially owing to a greater contribution from maturational factors.

\section{PRACTICAL APPLICATIONS}

The current results advocate the use of 4 compound (1) and core exercises in supporting strength and power (36) in this population. Exercises consisted of 3 sets of 8-12 repetitions (or up to 1 minute on timed exercises) and participants were encouraged to increase repetitions to more challenging ranges when possible. Twice-weekly resistance training sessions of 30 minutes duration is sufficient to provide the necessary stimulus. However, adaptations of Post-PHV youth may be larger than those in Pre-PHV.

Less experienced youth can engage in a general programme of integrative neuromuscular training to lay a foundation of technical competency for higher training loads and volumes as they mature. Mature youth who have undergone appropriate foundational training can engage in more advanced training techniques and can be exposed to higher training loads and volumes. Given that Pre-PHV youth may adapt at a lower magnitude, it may be more appropriate to subject them to alternative types of neuromuscular training (12) to yield increases in performance. Such training is considered a prerequisite to further participation in physical activity and is representative of a more focused approach to athletic development. In summary, youth of all ages can engage in resistance training but 
continuum.

412

\section{Acknowledgments}

This research received no funding from any external body.

\section{Conflicts of interest}

There are no conflicts of interest.

\section{REFERENCES}

1. Beardsley $\mathrm{C}$ and Contreras $\mathrm{B}$. The increasing role of the hip extensor musculature with heavier compound lower-body movements and more explosive sport actions. Strength Cond J 36: 49-55, 2014.

2. Beckham G, Mizuguchi S, Carter C, Sato K, Ramsey M, Lamont H, Hornsby G, Haff $G$, and Stone M. Relationships of isometric mid-thigh pull variables to weightlifting performance. J Sports Med Phys Fitness 53: 573-581, 2013.

3. Behringer M, Vom Heede A, Matthews M, and Mester J. Effects of strength training on motor performance skills in children and adolescents: a meta-analysis. Pediatr Exerc Sci 23: 186-206, 2011.

4. Buchheit M, Mendez-Villanueva A, Quod M, Quesnel T, and Ahmaidi S. Improving acceleration and repeated sprint ability in well-trained adolescent handball players: speed versus sprint interval training. Int J Sports Physiol Perform 5: 152-164, 2010.

5. Cohen DD, Voss C, Taylor MJ, Stasinopoulos DM, Delextrat A, and Sandercock GR. Handgrip strength in English schoolchildren. Acta Paediatr 99: 1065-1072, 2010.

6. Comfort P, Jones PA, McMahon JJ, and Newton R. Effect of knee and trunk angle on kinetic variables during the isometric midthigh pull: test-retest reliability. Int J Sports Physiol Perform 10: 58-63, 2015.

7. Comfort P, Stewart A, Bloom L, and Clarkson B. Relationships between strength, sprint, and jump performance in well-trained youth soccer players. J Strength Cond Res 28: 173-177, 2014.

8. Dabbs NC, Muñoz CX, Tran TT, and Brown LE. Effect of Rest Interval Following Whole-Body Vibration on Vertical Jump Performance. J Strength Cond Res 25: S60S61, 2011. 
9. Dahab KS and McCambridge TM. Strength training in children and adolescents: raising the bar for young athletes? Sports Health 1: 223-226, 2009.

10. Day ML, McGuigan MR, Brice $\mathrm{G}$, and Foster $\mathrm{C}$. Monitoring exercise intensity during resistance training using the session RPE scale. J Strength Cond Res 18: 353-358, 2004.

11. España-Romero V, Artero EG, Santaliestra-Pasias AM, Gutierrez A, Castillo MJ, and Ruiz JR. Hand span influences optimal grip span in boys and girls aged 6 to 12 years. J Hand Surg 33: 378-384, 2008.

12. Faigenbaum AD, Farrell A, Fabiano M, Radler T, Naclerio F, Ratamess NA, Kang J, and Myer GD. Effects of integrative neuromuscular training on fitness performance in children. Pediatr Exerc Sci 23: 573-584, 2011.

13. Faigenbaum AD, Kraemer WJ, Blimkie CJ, Jeffreys I, Micheli LJ, Nitka M, and Rowland TW. Youth resistance training: updated position statement paper from the national strength and conditioning association. J Strength Cond Res 23: S60-S79, 2009.

14. Faigenbaum AD, Lloyd RS, MacDonald J, and Myer GD. Citius, Altius, Fortius: beneficial effects of resistance training for young athletes: Narrative review. $\mathrm{Br} \mathrm{J}$ Sports Med 50: 3-7, 2016.

15. Faigenbaum AD, Milliken LA, Loud RL, Burak BT, Doherty CL, and Westcott WL. Comparison of 1 and 2 days per week of strength training in children. Res $Q$ Exercise Sport 73: 416-424, 2002.

16. Faigenbaum $\mathrm{AD}$ and Myer GD. Resistance training among young athletes: safety, efficacy and injury prevention effects. Br J Sports Med 44: 56-63, 2010.

17. Fernandez-Fernandez J, Sanz-Rivas D, Kovacs MS, and Moya M. In-season effect of a combined repeated sprint and explosive strength training program on elite junior tennis players. J Strength Cond Res 29: 351-357, 2015.

18. Folland JP and Williams AG. Morphological and neurological contributions to increased strength. Sports Med 37: 145-168, 2007.

19. Foster C, Daines E, Hector L, Snyder AC, and Welsh R. Athletic performance in relation to training load. Wis Med J 95: 370-374, 1996.

20. Franco-Márquez F, Rodríguez-Rosell D, González-Suárez J, Pareja-Blanco F, MoraCustodio R, Yañez-García J, and González-Badillo J. Effects of combined resistance training and plyometrics on physical performance in young soccer players. Int $J$ Sports Med 36: 906-914, 2015. 
21. Gonzalez-Badillo JJ, Pareja-Blanco F, Rodriguez-Rosell D, Abad-Herencia JL, Del Ojo-Lopez JJ, and Sanchez-Medina L. Effects of velocity-based resistance training on young soccer players of different ages. J Strength Cond Res 29: 1329-1338, 2015.

22. Hara M, Shibayama A, Takeshita D, Hay DC, and Fukashiro S. A comparison of the mechanical effect of arm swing and countermovement on the lower extremities in vertical jumping. Hum Mov Sci 27: 636-648, 2008.

23. Hopkins W. A Spreadsheet for Deriving a Confidence Interval, Mechanistic Inference and Clinical Inference from a P Value. Sportscience 11: 16-20, 2007.

24. Hopkins W, Marshall S, Batterham A, and Hanin J. Progressive statistics for studies in sports medicine and exercise science. Med Sci Sports Exerc 41: 3-13, 2009.

25. Hopkins WG. Estimating Sample Size for Magnitude-Based Inferences. Sportscience: 63-70, 2006.

26. Kelleher AR, Hackney KJ, Fairchild TJ, Keslacy S, and Ploutz-Snyder LL. The metabolic costs of reciprocal supersets vs. traditional resistance exercise in young recreationally active adults. J Strength Cond Res 24: 1043-1051, 2010.

27. Khamis $\mathrm{HJ}$ and Roche AF. Predicting adult stature without using skeletal age: the Khamis-Roche method. Pediatrics 94: 504-507, 1994.

28. Kibele A and Behm DG. Seven weeks of instability and traditional resistance training effects on strength, balance and functional performance. J Strength Cond Res 23: 2443-2450, 2009.

29. Knuttgen HG and Komi PV. Basic Considerations for Exercise, in: Strength and Power in Sport. P Komi, ed. Oxford: Blackwell Science Ltd, 2003.

30. Lesinski M, Prieske O, and Granacher U. Effects and dose-response relationships of resistance training on physical performance in youth athletes: a systematic review and meta-analysis. Br J Sports Med doi:10.1136/bjsports-2015-095497: In Press, 2016.

31. Lillegard WA, Brown EW, Wilson DJ, Henderson R, and Lewis E. Efficacy of strength training in prepubescent to early postpubescent males and females: effects of gender and maturity. Pediatr Rehabil 1: 147-157, 1997.

32. Lloyd RS, Faigenbaum AD, Stone MH, Oliver JL, Jeffreys I, Moody JA, Brewer C, Pierce KC, McCambridge TM, and Howard R. Position statement on youth resistance training: the 2014 International Consensus. Br J Sports Med: bjsports-2013-092952, 2013. 
33. Lloyd RS, Radnor JM, De Ste Croix MB, Cronin JB, and Oliver JL. Changes in Sprint and Jump Performances After Traditional, Plyometric, and Combined Resistance Training in Male Youth Pre- and Post-Peak Height Velocity. J Strength Cond Res 30: 1239-1247, 2016.

34. Martin RJ, Dore E, Twisk J, van Praagh E, Hautier CA, and Bedu M. Longitudinal changes of maximal short-term peak power in girls and boys during growth. Med Sci Sports Exerc 36: 498-503, 2004.

35. McBride JM, McCaulley GO, Cormie P, Nuzzo JL, Cavill MJ, and Triplett NT. Comparison of methods to quantify volume during resistance exercise. J Strength Cond Res 23: 106-110, 2009.

36. McGill S. Core training: Evidence translating to better performance and injury prevention. Strength Cond J 32: 33-46, 2010.

37. McGuigan MR and Winchester JB. The relationship between isometric and dynamic strength in college football players. J Sports Sci Med 7: 101-105, 2008.

38. McNarry MA, Lloyd RS, Buchheit M, Williams CA, and Oliver JL. The BASES Expert Statement on Trainability during Childhood and Adolescence. Sport Exerc Sci 4: 2223, 2014.

39. McNeal JR and Sands WA. Acute static stretching reduces lower extremity power in trained children. Pediatr Exerc Sci 15: 139-145, 2003.

40. Meylan CM, Cronin JB, Oliver JL, Hopkins WG, and Contreras B. The effect of maturation on adaptations to strength training and detraining in 11-15-year-olds. Scand J Med Sci Sports 24: e156-164, 2014.

41. Mirwald RL, Baxter-Jones AD, Bailey DA, and Beunen GP. An assessment of maturity from anthropometric measurements. Med Sci Sports Exerc 34: 689-694, 2002.

42. Moran J, Sandercock GRH, Ramírez-Campillo R, Meylan CM, Collison J, and Parry DAP. Age-related variation in male youth athletes' countermovement jump following plyometric training: a meta-analysis of controlled trials. J Strength Cond Res: In Press, 2016.

43. Moran J, Sandercock GRH, Ramírez-Campillo R, Meylan CM, Collison J, and Parry DAP. A meta-analysis of maturation-related variation in adolescent boy athletes' adaptations to short-term resistance training J Sport Sci: In Press, 2016. 
44. Naughton G, Farpour-Lambert NJ, Carlson J, Bradney M, and Van Praagh E. Physiological issues surrounding the performance of adolescent athletes. Sports Med 30: 309-325, 2000.

45. Nuzzo JL, McBride JM, Cormie P, and McCaulley GO. Relationship between countermovement jump performance and multijoint isometric and dynamic tests of strength. J Strength Cond Res 22: 699-707, 2008.

46. Ortega FB, Artero EG, Ruiz JR, Vicente-Rodriguez G, Bergman P, Hagströmer M, Ottevaere C, Nagy E, Konsta O, and Rey-Lopez J. Reliability of health-related physical fitness tests in European adolescents. The HELENA Study. Int $J$ Obes 32 : S49-S57, 2008.

47. Pfeiffer RD and Francis RS. Effects of Strength Training on Muscle Development in Prepubescent, Pubescent, and Postpubescent Males. Phys Sportsmed 14: 134-139, 1986.

48. Radnor JM, Lloyd RS, and Oliver JL. Individual Response To Different Forms Of Resistance Training In School Aged Boys. J Strength Cond Res: In Press, 2016.

49. Ramirez-Campillo R, Henriquez-Olguin C, Burgos C, Andrade D, Zapata D, Martinez C, Alvarez C, Baez El, Castro-Sepulveda M, Penailillo L, and Izquierdo M. Effect of Progressive Volume-Based Overload during Plyometric Training on Explosive and Endurance Performance in Young Soccer Players. J Strength Cond Res 29: 18841193, 2014.

50. Ramsay JA, Blimkie CJ, Smith K, Garner S, MacDougall JD, and Sale DG. Strength training effects in prepubescent boys. Med Sci Sports Exerc 22: 605-614, 1990.

51. Rhea MR. Determining the magnitude of treatment effects in strength training research through the use of the effect size. J Strength Cond Res 18: 918-920, 2004.

52. Rodriguez-Rosell D, Franco-Marquez F, Pareja-Blanco F, Mora-Custodio R, YáñezGarcía J, González-Suárez J, and González-Badillo J. Effects of 6-Weeks Resistance Training Combined With Plyometric and Speed Exercises on Physical Performance of Pre-Peak Height Velocity Soccer Players. Int J Sports Physiol Perform 11: 240-246, 2016.

53. Rumpf MC, Cronin JB, Mohamad IN, Mohamad S, Oliver JL, and Hughes MG. The effect of resisted sprint training on maximum sprint kinetics and kinematics in youth. Eur J Sport Sci 15: 374-381, 2015.

54. Rumpf MC, Cronin JB, Pinder SD, Oliver J, and Hughes M. Effect of different training methods on running sprint times in male youth. Pediatr Exerc Sci 24: 170-186, 2012. 
55. Santos EJ and Janeira MA. Effects of complex training on explosive strength in adolescent male basketball players. J Strength Cond Res 22: 903-909, 2008.

56. Spencer M, Fitzsimons M, Dawson B, Bishop D, and Goodman C. Reliability of a repeated-sprint test for field-hockey. J Sci Med Sport 9: 181-184, 2006.

57. Thomas C, Mather D, and Comfort P. Changes in sprint, change of direction and jump performance during a competitive season in male lacrosse players. J Athl Enhanc 3: 1-8, 2014.

58. Thompson A and Taylor BN. B.8 Factors for Units Listed Alphabetically. http://physics.nist.gov/Pubs/SP811/appenB8.html\#K Accessed Sep 23, 2016/.

59. Till K, Cobley S, O' Hara J, Cooke C, and Chapman C. Considering maturation status and relative age in the longitudinal evaluation of junior rugby league players. Scand $J$ Med Sci Sports 24: 569-576, 2014.

60. Vissing K, Brink M, Lonbro S, Sorensen H, Overgaard K, Danborg K, Mortensen J, Elstrom O, Rosenhoj N, Ringgaard S, Andersen JL, and Aagaard P. Muscle adaptations to plyometric vs. resistance training in untrained young men. J Strength Cond Res 22: 1799-1810, 2008.

61. Vrijens J. Muscle strength development in the pre-and post-pubescent age. Med Sport Sci 11: 152-158, 1978.

62. Waugh CM, Korff T, Fath F, and Blazevich AJ. Effects of resistance training on tendon mechanical properties and rapid force production in prepubertal children. $J$ Appl Physiol 117: 257-266, 2014.

63. Wrigley RD, Drust B, Stratton G, Atkinson G, and Gregson W. Long-term soccerspecific training enhances the rate of physical development of academy soccer players independent of maturation status. Int J Sports Med 35: 1090-1094, 2014.

64. Zatsiorsky V and Kraemer W. Science and practice of strength training. Champaign: Human Kinetics, 2006. 
Table 1 Descriptive data for participants

\begin{tabular}{|c|c|c|c|}
\hline Pre-PHV Group & Experimental $(n=14)$ & Control $(n=15)$ & Effect size \\
\hline Age (years) & $11.9 \pm 1.2$ & $11.3 \pm 1.2$ & $0.5(-0.1 \text { to } 1.1)_{\text {small }}$ \\
\hline Age range (years) & $10.4-13.2$ & $9.6-13.9$ & \\
\hline Maturity offset (years) & $-1.8 \pm 1.0$ & $-2.0 \pm 1.1$ & $0.2(-0.4 \text { to } 0.8)_{\text {trivial }}$ \\
\hline Height $(\mathrm{cm})$ & $152.5 \pm 6.6$ & $152.4 \pm 12.1$ & $0.0(-0.6 \text { to } 0.6)_{\text {trivial }}$ \\
\hline Sitting height $(\mathrm{cm})$ & $75.2 \pm 4.4$ & $75.5 \pm 5.6$ & $-0.1(-0.7 \text { to } 0.6)_{\text {trivial }}$ \\
\hline Mass (kg) & $44.7 \pm 10.0$ & $47.4 \pm 13.3$ & $-0.2(-0.8 \text { to } 0.4)_{\text {small }}$ \\
\hline Post-PHV Group & Experimental $(n=8)$ & Control $(n=7)$ & ize \\
\hline Age (years) & $15.0 \pm 1.1$ & $14.9 \pm 1.2$ & $0.1(-0.8 \text { to } 0.9)_{\text {trivial }}$ \\
\hline Age range (years) & $15.4-17.0$ & $14.7-17.5$ & \\
\hline Maturity offset (years) & $1.6 \pm 0.5$ & $1.2 \pm 1.0$ & $0.5(-0.3 \text { to } 1.4)_{\text {small }}$ \\
\hline Height $(\mathrm{cm})$ & $176.4 \pm 3.6$ & $173.9 \pm 6.5$ & $0.5(-0.4 \text { to } 1.3)_{\text {small }}$ \\
\hline \multirow[t]{2}{*}{ Sitting height (cm) } & $89.9 \pm 2.5$ & $87.1 \pm 3.7$ & 0.9 (0.0 to \\
\hline & & & $1.8)_{\text {moderate }}$ \\
\hline Mass $(\mathrm{kg})$ & 68.5 & $66.4 \pm 9.7$ & $0.3(-0.6 \text { to } 1.1)_{\text {small }}$ \\
\hline
\end{tabular}


Table 2 Resistance training programme

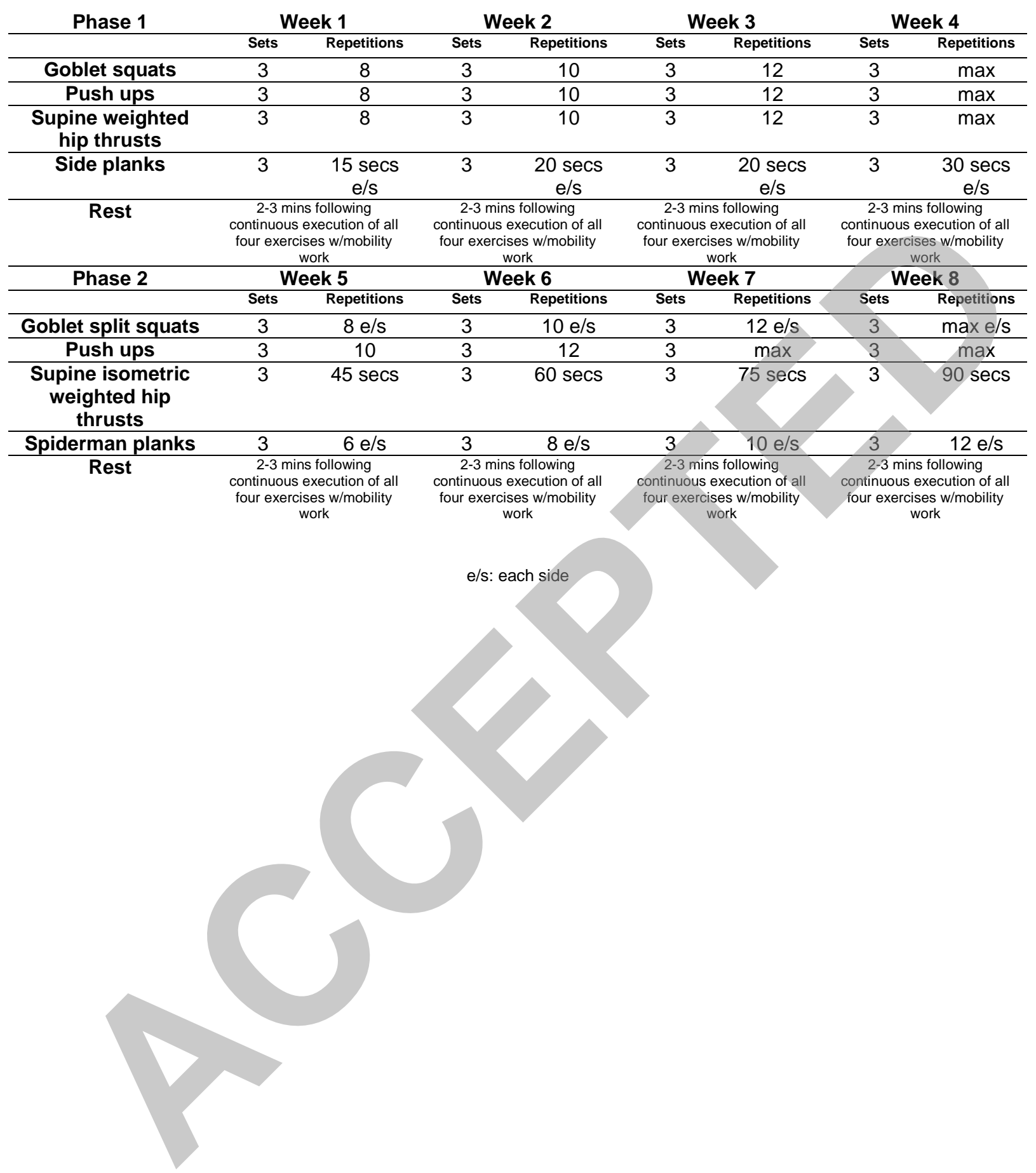




\begin{tabular}{|c|c|c|c|c|c|c|c|c|}
\hline Variable & Group & $\begin{array}{l}\text { Baseline } \\
\text { (SD) }\end{array}$ & $\begin{array}{l}\text { Follow-up } \\
\text { (SD) }\end{array}$ & $\begin{array}{l}\text { Effect } \\
\text { size }\end{array}$ & $\begin{array}{l}\text { Confidence } \\
\text { limits }\end{array}$ & $\begin{array}{l}\text { Likelihood } \\
\text { effect is } \\
\text { beneficial }\end{array}$ & $\begin{array}{l}\text { Effect } \\
\text { description }\end{array}$ & $\begin{array}{l}\text { Odds } \\
\text { ratio of } \\
\text { benefit to } \\
\text { harm }\end{array}$ \\
\hline \multirow[t]{6}{*}{$\begin{array}{l}\text { Mid-thigh } \\
\text { pull (kgf) }\end{array}$} & $\begin{array}{l}\text { All } \\
\text { (Experimental) }\end{array}$ & $94.9(35.1)$ & $\begin{array}{l}115.6 \\
(38.3) \\
\end{array}$ & 0.6 & 0.1 to 1.1 & $86.1 \%$ & $\begin{array}{l}\text { Small } \\
\text { increase }\end{array}$ & 407 \\
\hline & All (Control) & $87.0(32.8)$ & 96.1 (33.3) & 0.3 & -0.2 to 0.8 & $67.9 \%$ & $\begin{array}{l}\text { Small } \\
\text { increase }\end{array}$ & 576 \\
\hline & $\begin{array}{l}\text { Pre-PHV } \\
\text { Experimental }\end{array}$ & $74.0(20.7)$ & $92.5(26.4)$ & 0.8 & 0.1 to 1.4 & $89.5 \%$ & $\begin{array}{l}\text { Moderate } \\
\text { increase }\end{array}$ & 374 \\
\hline & $\begin{array}{l}\text { Pre-PHV } \\
\text { Control }\end{array}$ & $78.2(30.2)$ & $82.0(28.1)$ & 0.1 & -0.5 to 0.7 & 1010 & $\begin{array}{l}\text { Trivial } \\
\text { increase }\end{array}$ & 828 \\
\hline & $\begin{array}{l}\text { Post-PHV } \\
\text { Experimental }\end{array}$ & $\begin{array}{l}131.3 \\
(22.6) \\
\end{array}$ & $\begin{array}{l}156.0 \\
(13.1) \\
\end{array}$ & 1.3 & 0.4 to 2.2 & $92.4 \%$ & $\begin{array}{l}\text { Large } \\
\text { increase }\end{array}$ & 359 \\
\hline & $\begin{array}{l}\text { Post-PHV } \\
\text { Control }\end{array}$ & $\begin{array}{l}105.9 \\
(32.1) \\
\end{array}$ & $\begin{array}{l}126.4 \\
(21.8) \\
\end{array}$ & 0.7 & -0.2 to 1.7 & $89.8 \%$ & $\begin{array}{l}\text { Moderate } \\
\text { increase }\end{array}$ & 350 \\
\hline \multirow[t]{6}{*}{$\begin{array}{l}\text { Hand grip } \\
\text { (kgf) }\end{array}$} & $\begin{array}{l}\text { All } \\
\text { (Experimental) }\end{array}$ & $27.8(10.6)$ & $27.6(9.8)$ & 0.0 & -0.5 to 0.5 & $0.0 \%$ & $\begin{array}{l}\text { Trivial } \\
\text { decrease }\end{array}$ & 0 \\
\hline & All (Control) & $24.8(9.0)$ & $25.0(7.7)$ & 0.0 & -0.5 to 0.5 & $0.0 \%$ & $\begin{array}{l}\text { Trivial } \\
\text { increase }\end{array}$ & 43 \\
\hline & $\begin{array}{l}\text { Pre-PHV } \\
\text { Experimental }\end{array}$ & $20.9(4.8)$ & $21.7(5.1)$ & 0.2 & -0.5 to 0.8 & $34.0 \%$ & $\begin{array}{l}\text { Trivial } \\
\text { increase }\end{array}$ & 636 \\
\hline & $\begin{array}{l}\text { Pre-PHV } \\
\text { Control }\end{array}$ & $20.3(5.4)$ & $21.2(5.3)$ & 0.2 & -0.4 to 0.8 & $37.2 \%$ & $\begin{array}{l}\text { Trivial } \\
\text { increase }\end{array}$ & 677 \\
\hline & $\begin{array}{l}\text { Post-PHV } \\
\text { Experimental }\end{array}$ & $39.9(5.6)$ & $37.9(6.7)$ & -0.3 & -1.2 to 0.5 & $0.9 \%$ & $\begin{array}{l}\text { Small } \\
\text { decrease }\end{array}$ & 0 \\
\hline & $\begin{array}{l}\text { Post-PHV } \\
\text { Control }\end{array}$ & $34.5(7.3)$ & $33.1(5.6)$ & -0.2 & -1.1 to 0.7 & $0.5 \%$ & $\begin{array}{l}\text { Small } \\
\text { decrease }\end{array}$ & 0 \\
\hline \multirow[t]{3}{*}{$\begin{array}{l}\text { Vertical } \\
\text { jump (cm) }\end{array}$} & $\begin{array}{l}\text { All } \\
\text { (Experimental) }\end{array}$ & $37.3(6.8)$ & $38.8(7.1)$ & 0.2 & -0.3 to 0.7 & $56.9 \%$ & $\begin{array}{l}\text { Small } \\
\text { increase }\end{array}$ & 713 \\
\hline & All (Control) & $32.9(6.2)$ & $32.0(7.4)$ & -0.1 & -0.6 to 0.4 & $0.0 \%$ & $\begin{array}{l}\text { Trivial } \\
\text { decrease }\end{array}$ & 0 \\
\hline & $\begin{array}{l}\text { Pre-PHV } \\
\text { Experimental }\end{array}$ & $35.6(7.0)$ & $36.8(7.3)$ & 0.2 & -0.5 to 0.8 & $37.0 \%$ & $\begin{array}{l}\text { Trivial } \\
\text { increase }\end{array}$ & 620 \\
\hline
\end{tabular}




\begin{tabular}{|c|c|c|c|c|c|c|c|}
\hline $\begin{array}{l}\text { Pre-PHV } \\
\text { Control }\end{array}$ & $30.7(5.4)$ & $28.9(5.4)$ & -0.3 & -0.9 to 0.3 & $0.7 \%$ & $\begin{array}{l}\text { Small } \\
\text { decrease }\end{array}$ & 0 \\
\hline $\begin{array}{l}\text { Post-PHV } \\
\text { Experimental }\end{array}$ & $40.1(5.7)$ & $42.4(5.4)$ & 0.4 & -0.4 to 1.2 & $82.0 \%$ & $\begin{array}{l}\text { Small } \\
\text { increase }\end{array}$ & 344 \\
\hline $\begin{array}{l}\text { Post-PHV } \\
\text { Control }\end{array}$ & $37.6(5.6)$ & $38.6(7.1)$ & 0.2 & -0.7 to 1.0 & $30.4 \%$ & $\begin{array}{l}\text { Trivial } \\
\text { increase }\end{array}$ & 196 \\
\hline
\end{tabular}

Table 3 Within-group analysis baseline and follow-up scores, percentage change, effect sizes, confidence limits, likelihood effects and odds ratios for performance data 


\begin{tabular}{|c|c|c|c|c|c|c|}
\hline Variable & Comparison & Effect size & $\begin{array}{l}\text { Confidence } \\
\text { limits }\end{array}$ & $\begin{array}{l}\text { Likelihood } \\
\text { effect is } \\
\text { beneficial }\end{array}$ & $\begin{array}{l}\text { Effect } \\
\text { description }\end{array}$ & $\begin{array}{l}\text { Odds ratio } \\
\text { of benefit } \\
\text { to harm }\end{array}$ \\
\hline \multirow[t]{3}{*}{$\begin{array}{l}\text { Mid-thigh } \\
\text { pull (kgf) }\end{array}$} & $\begin{array}{l}\text { Experimental } \\
\text { vs. Control } \\
\text { (All) }\end{array}$ & 0.5 & 0.0 to 1.0 & $85.5 \%$ & $\begin{array}{l}\text { Small } \\
\text { increase }\end{array}$ & 411 \\
\hline & $\begin{array}{l}\text { Experimental } \\
\text { vs. Control } \\
\text { (Pre-PHV) }\end{array}$ & 0.4 & -0.2 to 1.0 & $79.0 \%$ & $\begin{array}{l}\text { Small } \\
\text { increase }\end{array}$ & 486 \\
\hline & $\begin{array}{l}\text { Experimental } \\
\text { vs. Control } \\
\text { (Post-PHV) }\end{array}$ & 1.7 & 0.7 to 2.7 & $92.9 \%$ & Large & 364 \\
\hline \multirow[t]{3}{*}{$\begin{array}{l}\text { Hand grip } \\
\text { (kgf) }\end{array}$} & $\begin{array}{l}\text { Experimental } \\
\text { vs. Control } \\
\text { (All) }\end{array}$ & 0.3 & -0.2 to 0.8 & $71.4 \%$ & $\begin{array}{l}\text { Small } \\
\text { increase }\end{array}$ & 540 \\
\hline & $\begin{array}{l}\text { Experimental } \\
\text { vs. Control } \\
\text { (Pre-PHV) }\end{array}$ & 0.1 & & $3.8 \%$ & $\begin{array}{l}\text { Trivial } \\
\text { increase }\end{array}$ & 5092 \\
\hline & $\begin{array}{l}\text { Experimental } \\
\text { vs. Control } \\
\text { (Post-PHV) }\end{array}$ & 0.8 & $71+017$ & $89.4 \%$ & $\begin{array}{l}\text { Moderate } \\
\text { increase }\end{array}$ & 374 \\
\hline \multirow[t]{3}{*}{$\begin{array}{l}\text { Vertical } \\
\text { jump (cm) }\end{array}$} & $\begin{array}{l}\text { Experimental } \\
\text { vs. Control } \\
\text { (All) }\end{array}$ & 0.9 & 0.4 to 1.5 & $90.5 \%$ & $\begin{array}{l}\text { Moderate } \\
\text { increase }\end{array}$ & 377 \\
\hline & $\begin{array}{l}\text { Experimental } \\
\text { vs. Control } \\
\text { (Pre-PHV) }\end{array}$ & 1.2 & 0.6 to 1.9 & $91.8 \%$ & $\begin{array}{l}\text { Large } \\
\text { increase }\end{array}$ & 372 \\
\hline & $\begin{array}{l}\text { Experimental } \\
\text { vs. Control } \\
\text { (Post-PHV) }\end{array}$ & 0.6 & -0.3 to 1.5 & $87.2 \%$ & $\begin{array}{l}\text { Moderate } \\
\text { increase }\end{array}$ & 383 \\
\hline
\end{tabular}

Table 4 Between-group analysis effect sizes, confidence limits, likelihood effects and odds ratios for performance data 
Table 5 Descriptive data for training load

\begin{tabular}{ccccc} 
& All & Pre-PHV & Post-PHV & Effect size \\
\hline $\begin{array}{c}\text { Mean session duration } \\
\text { (mins) }\end{array}$ & $31.0 \pm 3.2$ & $31.0 \pm 3.1$ & $30.9 \pm 3.3$ & $0.0(-0.8 \text { to } 0.7)_{\text {trivial }}$ \\
Mean RPE & & & \\
\hline $\begin{array}{c}\text { Mean session load } \\
\text { (AU) }\end{array}$ & $204.8 \pm 38.0$ & $200.4 \pm 38.1$ & $212.8 \pm 36.6$ & $0.3(-0.4 \text { to } 1.1)_{\text {small }}$ \\
& & & \\
\hline Mean attendance $(\%)$ & $89.2 \pm 7.8$ & $89.7 \pm 8.7$ & $88.3 \pm 6.2$ & $-0.2(-0.9 \text { to } 0.6)_{\text {trivial }}$ \\
\hline
\end{tabular}




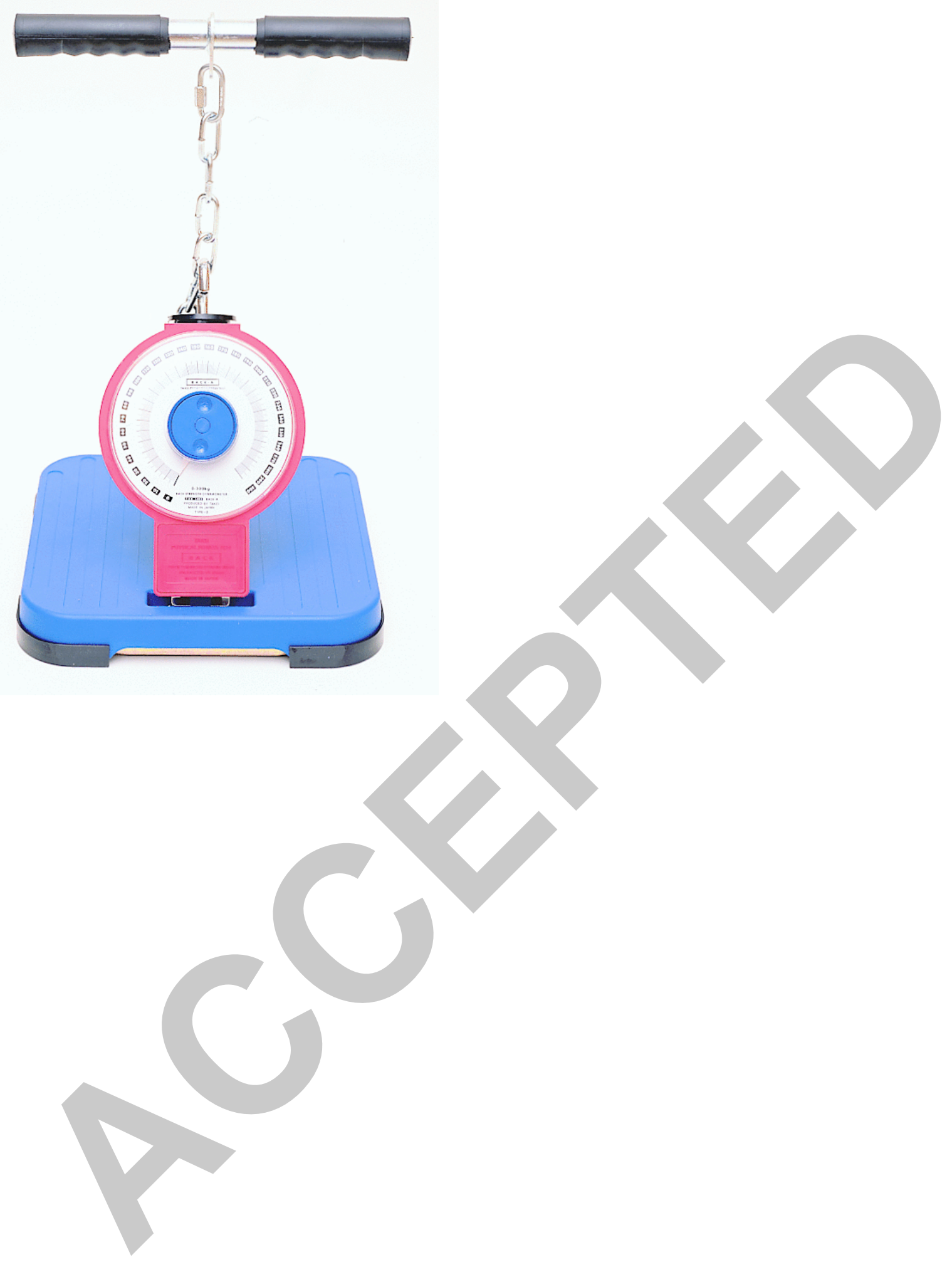




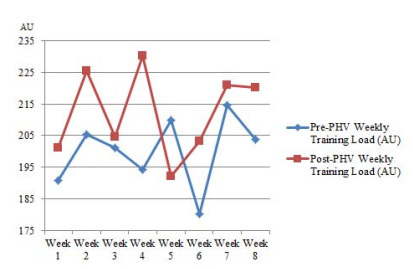

